\title{
The pathotype structure of the causative agent Puccinia sp. tritici in Kazakhstan
}

\author{
Rsaliyev A.S., Baygutov M.Zh., Maulenbay A.D. \\ Research Institute for Biological Safety Problems, Gvardeisky, Korday District, Zhambyl Region, \\ Kazakhstan \\ *email: aralbek@mail.ru
}

The wheat yellow rust (causative agent - obligate fungus Puccinia striiformis $\mathrm{f}$. sp. tritici) occurs practically every year in Kazakhstan and other Central Asian countries. In 2018 and 2019 year, to determine the development of wheat yellow rust, as well as to collect samples of the pathogen populations the main grain-producing regions of Kazakhstan surveyed. Surveying areas and collecting samples of the pathogen population had held as a part of the route of the expedition, as well as individually. In 2018 and 2019, yellow rust has been observed in the southern and southeastern regions of the Kazakhstan, where mainly winter wheat cultivars cultivated. The development of the pathogen in these regions varied from moderate to severe. The disease developed severely on industrial crops in certain areas of the Almaty, Zhambyl and Turkestan regions, while the damage degree of the disease was in the range of 60-70\%.

The pathotypes of $P$. striiformis $\mathrm{f}$. sp. tritici were identified using International and European sets of differential cultivars in 2018 and 2019. In the analysis of 101 single pustule isolates of $P$. striiformis f. sp. tritici in the Kazakhstan regions, 21 pathotypes of the fungus were identified, which unevenly distributed between populations. In the south and southeast of Kazakhstan in 2018-2019, the predominant pathotypes of the pathogen were 66E35, 39E158, 79E186 and 79E104. The most dangerous pathotypes in Kazakhstan are 39E158, 79E27, 79E43, 79E143, 79E155, 79E186 and 111E158 with virulence of $60.0-73.3 \%$ to differential cultivars of the yellow rust. Among them, pathotypes 39E158, 79E143, and 111E158 were found in early studies and formed the basis of the synthetic population of the yellow rust when determining the resistance of wheat cultivars against an infectious background. 